\title{
Sediment physico-chemistry associated with natural marsh development on a storm-deposited sand flat
}

\author{
David T. Osgood, Marcio C. F. V. Santos*, Joseph C. Zieman \\ University of Virginia, Department of Environmental Sciences, Clark Hall, Charlottesville, Virginia 22903, USA
}

\begin{abstract}
Intertidal sediment physico-chemistry was compared at 2 naturally developing barrier island marshes in Virginia, USA. One site was located on the intertidal portion of a sand flat, deposited during a coastal storm in October 1991. The other site was an undisturbed, fringing marsh aged at 14 to 16 уг. Three sampling stations were established at equivalent elevations at both sites. At the marsh site, these sampling stations represented tall and short forms of Spartina alterniflora (low and intermediate elevation stations) and a high marsh zone of mostly Spartina patens (high elevation station). At both sites, sediment across the intertidal zone was characterized by $<1.5 \%$ organic matter and $>90 \%$ sand. Relative to the marsh site, the sand flat site had significantly higher pore water salinity and redox potential at the upper elevation stations, higher $\mathrm{pH}$ at all stations, and lower hydrogen sulfide at the 2 lower elevation stations. Organically bound nutrients generally were higher in the root zone of the marsh site, but inorganic nutrients were an order of magnitude higher at the low elevation station of the sand flat compared to all stations at the marsh site. The higher concentration of nutrients at the sand flat site may arise from a nutrient-rich mud flat buried during the storm event. This high concentration of nutrients could serve as an external nutrient source to the root zone of the developing marsh and may also lead to a net export of inorganic nutrients to the flooding tidal water. A predictable zonation of intertidal vegetation on the sand flat should exist given the present patterns in sediment physico-chemistry. Based on nutrient standing stocks, the most favorable growing conditions for $S$. alterniflora exist at the low elevation station of the sand flat, where the tall form of this species is expected to dominate. The short form of $S$. alterniflora is expected to colonize the intermediate elevation station. A mixed community of species (S. patens, Distichlis spicata) probably will develop at the high elevation station, where the sediment is most oxidized. Vegetation zonation at the marsh site was not readily explained by patterns in sediment physico-chemistry measured in this study. Current research by the authors indicates that nutrient dynamics, controlled by subsurface hydrology, dictates nutrient supply at the marsh site and leads to a higher exposure to nutrients in the root zone of the tall form of $S$. alterniflora. The present study represents one of few involving measurements of sediment physico-chemistry in naturally developing marshes during the initial stages of development.
\end{abstract}

KEY WORDS: Salt marsh $\cdot$ Succession $\cdot$ Nutrients $\cdot$ Barrier islands

\section{INTRODUCTION}

Barrier islands are dynamic environments which are continually undergoing landscape-scale changes (Hayden et al. 1991). Over time, movement of typical transgressive estuaries leads to a system characterized

\footnotetext{
- Present address: Labohidro-UFMA, Largo Dos Amores 21. São Luis, Maranhāo, 65020-240 Brazil
}

by marshes that range in relative age from younger at the land margin to older at the oceanic interface (Dame et al. 1992). On barrier islands, this chronosequence may be overlain with a mosaic of different-age marshes originating from movement of sediment associated with inlet dynamics and overwash events (Godfrey \& Godfrey 1976). Young barrier island/lagoon marshes are characterized by sediment with a high sand and low organic component, generally lack welldeveloped surface drainage patterns, and have a rela- 
tively large percentage of low marsh (Godfrey \& Godfrey 1976, Frey \& Basan 1978). Older marshes are characterized by finer-grained, organic-rich sediment intersected by a well-developed system of tidal creeks with a greater percentage of high marsh (Redfield 1972, Godfrey \& Godfrey 1976. Frey \& Basan 1978). While some work has been accomplished to describe geomorphology and basic ecological characteristics, the state of our understanding of ecosystem processes associated with natural marsh development is poor (Morris 1988, Odum 1988, Osgood \& Zieman 1993).

An important topic in the estuarine literature involves questions of import and export of nutrients and other tidal water constituents to and from marshes and estuaries. This question has been addressed within individual marshes as a function of elevation, tidal flooding frequency, and vegetation type (Nixon 1980, Wolaver \& Zieman 1984). More recently, the question of nutrient flux has been viewed on an estuary-wide scale as a function of marsh age (Childers et al. 1993). Consistent with the ecosystem development hypotheses of Odum (1969) and Vitousek \& Reiners (1975), natural young marshes have been shown to import nutrients as opposed to natural older marshes which export nutrients (Valiela \& Teal 1979, Childers et al. 1993). The effectiveness of young, created marshes to sequester nutrients, on the basis of sediment type, has also been investigated (Craft et al. 1989, Gale et al. 1993).

Osgood \& Zieman (1993) demonstrated that nutrient concentrations were similar in the top $10 \mathrm{~cm}$ of a natural, 10 to 13 yr old marsh compared to a natural marsh that was hundreds of years old. However, it is unclear at what point the root zone nutrient pools were equivalent between the 2 marshes in this latter study. Redfield (1972) stated that a mature stand of Spartina alterniflora can develop in as little as 4 to 5 yr. Does sediment physico-chemistry also change significantly in as short a time? We still know little about the initial stages of natural marsh development, especially in terms of general sediment chemistry and development of organic and inorganic nutrient standing stocks.

The dynamic nature of the barrier island environment makes it an appropriate setting in which to study initial stages of natural marsh development. In late October 1991, a severe coastal storm occurred along the U.S. Mid-Atlantic Coast. The combination of a low pressure system with the remnants of Hurricane Grace created a northeaster of unusual duration and intensity that was recorded as one of the worst storms on the Atlantic Coast in 50 yr (Davis \& Dolan 1992). The Virginia barrier islands were substantially affected by this event and detailed records of sediment deposition of one particular overwash event on South Parramore Island have created a unique opportunity to study intertidal emergent macrophyte colonization and sediment characteristics from the initial stages of deposition.

In this study, we measured organic and inorganic fractions of nutrient standing stocks and general sediment physico-chemistry within and below the root zone (10 and $40 \mathrm{~cm}$, respectively) along 2 intertidal transects at 3 different elevations at the stormdeposited sand flat. For comparative purposes, the same measurements were made in a vegetated marsh of a more advanced developmental stage with welldeveloped vegetation zonation. Spartina alterniflora production of the tall and short growth forms was also measured at the marsh site. The results of this study are discussed with reference to findings by other studies involving nutrient flux to and from developing and mature marsh ecosystems. Also discussed are the effects of sediment chemistry on the future vegetation colonization and intertidal zonation on the sand flat.

\section{METHODS}

Site description and transect survey. This study was conducted at 2 adjacent barrier islands located within the Virginia Coast Reserve/Long-Term Ecological Research site, approximately $10 \mathrm{~km}$ off the eastern shore of Virginia. The sand flat site was located on South Parramore Island (Fig. 1). The sand flat was deposited as part of an extensive overwash fan during a coastal storm in late October 1991. Reshaping of the flat took place during the winters following the storm. The marsh site was located at the south end of Hog Island (Fig. 1). This site was aged at 14 to $16 \mathrm{yr}$ by aerial photography. As with other young sites in the area, it was a fully vegetated, fringing marsh (approximately $50 \mathrm{~m}$ wide) devoid of well-developed drainage channels.

Sampling stations on 2 parallel transects, running the length of the intertidal zone, were installed to reflect the average elevation of the main vegetation zones at the marsh site on South Hog Island. The first 2 of these stations represented the tall and short growth forms of Spartina alterniflora. The third station was characterized by high marsh species (a mixed community of Limonium carolinium and Salicornia virginica with Spartina patens and Distichlis spicata bordering the high marsh zone on the upland interface). These stations will be referred to, respectively, as the low, intermediate, and high elevation stations at both sites. Beginning in June 1993, the area surrounding the 2 lower stations of the sand flat site was being colonized by sparse $S$. alterniflora and near the high elevation stations by a few plants each of $S$. patens and $D$. spicata (D. Osgood pers. obs.). Actual density or pro- 


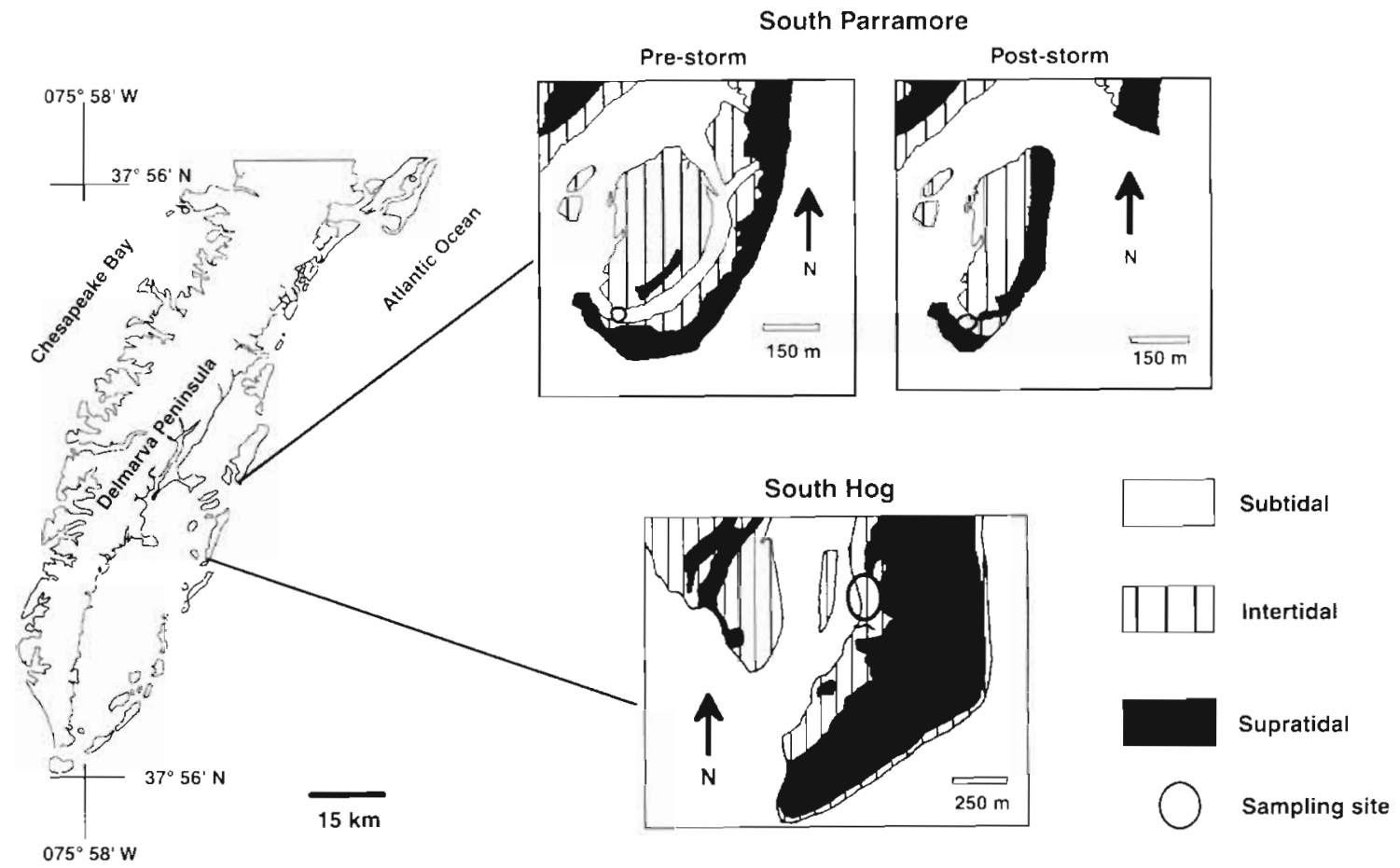

Fig. 1 Delmarva Peninsula, Virginia, USA, showing locations of the sand flat site on South Parramore Island in both pre- and post-storm conditions and the young marsh site on South Hog Island

duction of the colonizing vegetation was not quantified, but we estimate density at 1 to 2 plants $\mathrm{m}^{-2}$.

Table 1 summarizes topographic and tidal flooding data for the stations at both sites and the main vegetation zonation boundaries at the South Hog marsh site. Benchmarks at the 2 sites were topographically tied to each other and to USGS (U.S. Geological Survey) benchmarks at the mainland using Survey Grade GPS (Global Positioning System). The reference datum adopted here is the USGS 1967 Reduction Level. The benchmarks, at each site, were used as references in the topographic survey and determination of the eleva- tion of the main vegetation zonation boundaries. An autolevel and survey rod were employed with a survey accuracy of $0.5 \mathrm{~cm}$.

The utilization of a common topographic datum and an undisturbed, GPS-referenced benchmark made possible the establishment of the sampling stations on the sand flat transects at the same topographic height as those at the marsh site. This allowed for the direct comparison of 2 intertidal zones, exposed to the same degree of tidal influence. Tidal height data for 1993 (Krovetz et al. 1993), sampled at 12 min intervals at a North Hog tidal station, also tied to the benchmark net-

Table 1. Elevation and tidal flooding characteristics of sampling stations (in bold type) at sand flat and marsh site, along with main vegetation boundaries at the marsh site. MHW: Mean High Water; MHWNT: Mean High Water Neap Tide; MSL: Mean Sea Level

\begin{tabular}{|c|c|c|c|c|}
\hline Description & $\begin{array}{l}\text { Approximate } \\
\text { tidal datum }\end{array}$ & $\begin{array}{c}\text { USGS } \\
\text { elevation } \\
\text { (m) }\end{array}$ & $\begin{array}{l}\text { Tidal flooding } \\
\text { frequency } \\
\text { (tides } \mathrm{yr}^{-1} \text { ) }\end{array}$ & $\begin{array}{c}\text { Tidal flooding } \\
\text { duration } \\
\left(\mathrm{h} \mathrm{yr}^{-1}\right)\end{array}$ \\
\hline High marsh upper boundary & $\mathrm{MHW}$ & 0.831 & 312 & 934 \\
\hline High elevation sampling station & & 0.816 & 324 & 998 \\
\hline Short-form Spartina aiterniflora - high marsh boundary & MHWNT & 0.600 & 540 & 2124 \\
\hline Intermediate elevation sampling station & & 0.498 & 588 & 2767 \\
\hline Tall-form - short-form Spartina alterniflora boundary & & 0.339 & 684 & 3866 \\
\hline Low elevation sampling station & MSL & 0.266 & 684 & 4260 \\
\hline Tall-form Spartina alterniflora - mudflat boundary & & -0.230 & 720 & 7723 \\
\hline
\end{tabular}


work, were used to determine tidal flooding duration and frequency at the 2 sites. Tidal data were also used to compute tidal harmonic constants, which were used in the determination of the tidal datums.

Pre-and post-storm survey on South Parramore also allowed for determination of depth of storm deposition in the immediate area of the transects. There was approximately $70 \mathrm{~cm}$ of deposition over the mudflat at the low elevation station and $120 \mathrm{~cm}$ of deposition at the high elevation station.

Primary production. Aerial above-ground primary production of Spartina alterniflora from May to October 1993 was measured at the marsh site using the census method of Morris \& Haskin (1990). The census involved monthly measuring of height of all plant stems in six $0.25 \mathrm{~m}^{2}$ plots at the low and intermediate elevation stations (a total of 12 plots). Change in biomass over the growing season was calculated from change in height using a regression plot of biomass vs height generated from 50 plants collected at each station in May and again in September 1993. Production is reported as $\mathrm{g}$ dry biomass $\mathrm{m}^{-2}$ (growing season) ${ }^{-1}$. Maximum stem density (stems $\mathrm{m}^{-2}$ ) for each station was calculated from the month with the highest stem density and reported as the average for the 6 plots.

Sediment physico-chemistry. Measurements included sediment grain size and organic content; soluble, inorganic and organic sediment nitrogen and phosphorus; pore water salinity, $\mathrm{pH}$, redox potential, hydrogen sulfide, and iron. All analyses were made monthly from May to October 1993, with the exception of grain size and organic content, which were sampled in May, redox potential, which was sampled in June and August, and nitrate/nitrite, which was sampled in August. All measurements were made at 10 and $40 \mathrm{~cm}$ below the sediment surface at all stations.

Grain size distribution and organic content were measured in a subsample from 3 replicate cores collected at each station (7.62 cm i.d.). Grain size distribution was determined using the soil hydrometer method (Brower \& Zar 1984). Thirty grams (dry weight) of sediment was reacted overnight with $30 \%$ hydrogen peroxide to oxidize organic matter. The sediment was then washed thoroughly prior to analysis for percentages of sand, silt, and clay. Organic matter content was determined by percent loss of weight on ignition at $500^{\circ} \mathrm{C}$ for $6 \mathrm{~h}$.

Soluble ammonium and phosphate were measured colorimetrically using standard methods (Parsons et al. 1984) and total iron [Fe(II) and Fe(III)] was measured colorimetrically using the protocol of Gibbs (1979). Nitrate/nitrite were analyzed colorimetrically using a spongy cadmium method (Jones 1984). Pore water was collected from duplicate suction lysimeters at each depth at each station. The lysimeters are designed to sample water while maintaining ambient redox conditions (Chambers \& Odum 1990). Pore water was collected from the lysimeters via syringe and transferred through a $0.45 \mu \mathrm{m}$ membrane filter to evacuated tubes containing $0.1 \mathrm{ml}$ of $6 \mathrm{~N} \mathrm{HCl}$ to avoid ammonium volatilization. Sulfides were removed by effervescence with helium gas for $5 \mathrm{~min}$. To adjust $\mathrm{pH}, 0.1 \mathrm{ml}$ of $6 \mathrm{~N}$ $\mathrm{NaOH}$ was added to the ammonium samples just prior to reagent addition. All samples were analyzed within $6 \mathrm{~h}$ of collection.

Pore water from the suction lysimeters was also analyzed for redox potential, pH, salinity, and hydrogen sulfide. Redox potential was measured on water transferred via syringe to a flow-through cell equipped with a port for an Orion combination redox electrode. Platinum electrode potential $(\mathrm{mV})$ was read from an Orion $\mathrm{pH}$ meter and converted to redox potential by adding the potential for the $\mathrm{Ag} / \mathrm{AgCl}$, saturated $\mathrm{KCl}$ reference electrode (+199 mV) (Caton 1977). Pore water samples for $\mathrm{pH}$ and salinity were collected in $20 \mathrm{ml}$ vials and transported to the lab. pH was read within 6 h using an Orion combination $\mathrm{pH}$ electrode and an Orion $\mathrm{pH}$ meter. Salinity was measured using a temperaturecompensated refractometer. Hydrogen sulfide was measured using the Cline's reagent method (Cline 1969). Samples for hydrogen sulfide were transferred, via syringe, from the lysimeter immediately to evacuated tubes containing the appropriate volume of reagent. Samples were analyzed colorimetrically within $3 \mathrm{~h}$ of collection.

To assess the distribution of nutrients with depth at both sites, a depth profile was made at $30 \mathrm{~cm}$ intervals from 10 to $250 \mathrm{~cm}$ at each station on 1 transect from each site in August 1993. Galvanized metal well points and pipe were used to drive the well to the desired depth. A plastic sleeve was inserted into the well and also served as the conduit for samples, which were pumped to the surface by hand vacuum pump, before the well was driven to the next sampling depth. Three times the well volume was pumped at each sampling depth before the sample was collected. Analysis of soluble ammonium and phosphate was conducted as described above. Logistical constraints did not allow for replication of the wells at each station, therefore data are reported here as only a rough characterization of the nutrient profile. Grain size analysis, organic content, and insoluble nutrient fractions were not measured as part of the depth profile, which could have offered more information concerning the buried layer. Sediment redistribution during winter storms, following completion of the main study, precluded the ability to collect this data.

Sediment inorganic nutrients were measured in subsamples from 3 replicate cores collected at each station $(7.62 \mathrm{~cm}$ i.d.). $\mathrm{KCl}$ extraction was used to determine 
extractable ammonium from $20 \mathrm{~cm}^{3}$ of sediment (Haines et al. 1977). Total inorganic phosphorus was determined using a hot $\mathrm{HCl}$ extraction (see below).

Total sediment nitrogen was determined from duplicates of $15 \mathrm{mg}$ of oven-dried $\left(<40^{\circ} \mathrm{C}\right)$ sediment using a Carlo-Erba Nitrogen Analyzer 1500. Sediment organic nitrogen was then calculated by difference from the total sediment nitrogen measurement and the measured extractable ammonium. Extractable nitrate/nitrite was not accounted for in the calculation of organic nitrogen.

Duplicate $10 \mathrm{mg}$ subsamples were analyzed for total sediment phosphorus using a modification of a total particulate phosphorus method (Chambers \& Fourqurean 1991). The method employs ashing of the sample followed by a hot $\mathrm{HCl}$ extraction, then colorimetric analysis of soluble reactive phosphate. Total inorganic phosphorus was determined from duplicate samples run without the ashing step. The acid extraction provides a total inorganic value for phosphorus and does not allow for differentiation between various fractions of inorganic phosphorus, such as aluminum- or ironbound phosphorus. In addition, by not recovering some of these tightly bound forms of phosphorus, the weak acid extraction employed here may be underestimating total inorganic phosphorus. However, it should be providing an accurate estimate of the phosphorus pool available for uptake by vegetation. Organic phosphorus was determined by difference from the total phosphorus and the inorganic phosphorus concentrations. An NBS standard of estuarine sediment was not used to determine efficiency of extraction.

Data analysis. Significant differences $(p<0.05)$ between the sites, stations, and with depth were tested using a 3-way ANOVA. Paired contrasts were set up to differentiate between stations at different sites and between stations within each site. Where data were collected from more than 1 mo, the samples were pooled for analysis to address between and within site differences. The June and August collections of redox potential were analyzed separately. Significant differences in Spartina alterniflora production and maximum stem density between stations at the marsh site was tested using a 1-way ANOVA. All tests were performed using SuperANOVA statistical software (Abacus Concepts 1989).

\section{RESULTS}

\section{Physical characteristics}

Compared to older marshes on the Virginia barrier islands, both developing intertidal sites had lower overall organic content and higher sand content by a factor of up to 12 times and 2 times, respectively
(Osgood \& Zieman 1993). Between the 2 developing sites, there was a significantly higher organic content in the root zone $(10 \mathrm{~cm})$ at the marsh site compared to the sand flat site (Table 2 ). Both sites had similar grain size content, the exception being a significantly higher clay content at $40 \mathrm{~cm}$ at the sand flat site compared to the marsh site at all stations (Table 2). This coincided with a consistent increase in the percentage of clay from 10 to $40 \mathrm{~cm}$ at the sand flat site and a reverse of this trend at the marsh site. The differences with depth at each site were not statistically significant.

\section{Chemical characteristics}

There was a general trend of decreasing salinity later in the growing season at all stations at both sites (Fig. 2). Significantly higher pore water salinity was observed at the intermediate and high elevation stations of the sand flat site relative to the marsh site (Table 2). pH was consistently above neutrality at the sand flat site, with the highest values at the high elevation station (Table 2). pH at the marsh site was at or just below neutrality and significantly lower at all stations and depths compared to the sand flat site (Table 2). There was no consistent temporal trend in $\mathrm{pH}$ through the growing season at either site. Pore water hydrogen sulfide was considerably lower at these developing sites compared to older, finer-sediment marshes, where values can typically exceed $1 \mathrm{mM}$ (D. Osgood unpub. data; Table 2, Fig. 2). The highest values of sulfide were found at the low elevation station at the marsh site in conjunction with a significantly lower redox potential in the root zone $(10 \mathrm{~cm})$ (Table 2$)$. The lowest values were found at the high elevation stations which coincides with significantly higher redox potential at that station at both sites. Redox potential was also higher at both depths of the high elevation station at the sand flat site, compared to the marsh site, but hydrogen sulfide between the sites at this station was not significantly different. There was some evidence of greater variability in hydrogen sulfide during the growing season at the 2 lower stations of the marsh site (Fig. 2). As was expected, the dominant form of iron in the intertidal zone was Fe(II), with generally similar concentrations between sites, but with higher concentrations at the low and intermediate elevation stations at both sites (Table 2). There were no consistent temporal trends in dissolved iron over the growing season.

\section{Nutrient standing stocks}

Overall, the total nutrient standing stocks at these developing sites are lower than found in older marshes 
Table 2. Substrate characteristics of a storm-deposited sand flat and undisturbed marsh. Chemical data are average of 6 mo (May to October, 1993). '<' and ' $>$ ' indicate significant differences between stations $(p<0.05)$. SE given in parentheses

\begin{tabular}{|c|c|c|c|c|c|c|c|c|c|c|}
\hline & $\begin{array}{l}\text { Low } \\
\text { Elevation }\end{array}$ & & $\begin{array}{c}\text { Sand flat site } \\
\text { Intermediate } \\
\text { Elevation }\end{array}$ & & $\begin{array}{c}\text { High } \\
\text { Elevation }\end{array}$ & $\begin{array}{l}\text { Low } \\
\text { Elevation }\end{array}$ & & $\begin{array}{l}\text { Marsh site } \\
\text { Intermediate } \\
\text { Elevation }\end{array}$ & & $\begin{array}{c}\text { High } \\
\text { Elevation }\end{array}$ \\
\hline \multicolumn{11}{|l|}{ Physical } \\
\hline \multicolumn{11}{|l|}{ Sand $(\%)$} \\
\hline $10 \mathrm{~cm}$ & $90.5(0.05)$ & & $93.0(1.0)$ & & $90.5(0.5)$ & $90.5(2.5)$ & & $90.0(0.0)$ & & $93.0(1.0)$ \\
\hline $40 \mathrm{~cm}$ & $90.0(0.0)$ & & $\cdot 91.5(0.5)$ & & $\cdot 90.5(0.5)$ & $93.0(1.0)$ & & $96.0(2.0)$ & & $95.5(1.5)$ \\
\hline \multicolumn{11}{|l|}{ Silt $(\%)$} \\
\hline $10 \mathrm{~cm}$ & $1.0(0.1)$ & & $1.0(0.1)$ & & $1.5(0.5)$ & $2.5(1.5)$ & & $1.5(0.5)$ & & $1.0(1.0)$ \\
\hline $40 \mathrm{~cm}$ & $0.0(0.0)$ & & $0.5(0.5)$ & & $1.5(0.5)$ & $0.5(0.5)$ & & $0.0(0.0)$ & & $0.0(0.0)$ \\
\hline \multicolumn{11}{|l|}{ Clay $(\%)$} \\
\hline $10 \mathrm{~cm}$ & $8.5(0.5)$ & & $6.0(1.0)$ & & $8.0(1.0)$ & $7.0(1.0)$ & & $8.5(0.5)$ & & $6.0(2.0)$ \\
\hline $40 \mathrm{~cm}$ & $\cdot 10.0(0.0)$ & & $\cdot 8.0(0.0)$ & & $\cdot 8.0(0.0)$ & $6.5(0.5)$ & & $4.0(2.0)$ & & $4.5(1.5)$ \\
\hline \multicolumn{11}{|c|}{ Organic $(\%)$} \\
\hline $10 \mathrm{~cm}$ & $\cdot 0.4(0.02)$ & & $\cdot 0.4(0.04)$ & & $\cdot 0.2(0.04)$ & $1.1(0.1)$ & & $0.8(0.1)$ & & $0.8(0.2)$ \\
\hline $40 \mathrm{~cm}$ & $0.6(0.05)$ & & $0.4(0.04)$ & & $0.2(0.01)$ & $0.5(0.1)$ & & $0.4(0.04)$ & & $0.5(0.1)$ \\
\hline \multicolumn{11}{|c|}{ Chemical } \\
\hline \multicolumn{11}{|c|}{ Redox potential (mV) } \\
\hline $10 \mathrm{~cm}$ & $\cdot 59.0(4.4)$ & & $88.1(9.8)$ & $<$ & $\cdot 249.1(12.4)$ & $4.0(18.3)$ & $<$ & $74.5(8.5)$ & $<$ & $207.1(10.9)$ \\
\hline $40 \mathrm{~cm}$ & $73.9(2.7)$ & & $78.4(4.6)$ & $<$ & • $196.9(9.8)$ & $46.9(19.2)$ & & $76.5(4.4)$ & $<$ & $150.1(14.3)$ \\
\hline \multicolumn{11}{|c|}{ Salinity (ppt) } \\
\hline $10 \mathrm{~cm}$ & $33(0.4)$ & $<$ & $\cdot 35(0.6)$ & & $34(0.8)$ & $33(0.4)$ & $>$ & $30(0.7)$ & $<$ & $32(0.6)$ \\
\hline $40 \mathrm{~cm}$ & $33(0.4)$ & & $\cdot 34(0.5)$ & & $\cdot 34(0.6)$ & $33(0.6)$ & $>$ & $29(0.7)$ & & $29(0.5)$ \\
\hline \multicolumn{11}{|l|}{$\mathrm{pH}$} \\
\hline $10 \mathrm{~cm}$ & $\cdot 7.1(0.02)$ & & $\cdot 7.2(0.03)$ & $<$ & $\cdot 7.4(0.02)$ & $6.7(0.05)$ & $<$ & $6.9(0.03)$ & $>$ & $6.7(0.04)$ \\
\hline $40 \mathrm{~cm}$ & $\cdot 7.2(0.02)$ & & $\cdot 7.2\{0.03\}$ & $<$ & $\cdot 7.4(0.02)$ & $6.9(0.04)$ & $<$ & $7.0(0.03)$ & $>$ & $6.9(0.04)$ \\
\hline \multicolumn{11}{|c|}{$\mathrm{Fe}(\mathrm{II})(\mu \mathrm{M})$} \\
\hline $10 \mathrm{~cm}$ & $29.4(4.0)$ & & $25.7(3.3)$ & $>$ & $\cdot 0.7(0.2)$ & $26.0(2.5)$ & & $18.7(1.9)$ & $>$ & $10.7(2.5)$ \\
\hline $40 \mathrm{~cm}$ & $27.9(3.6)$ & & $26.5(3.7)$ & $>$ & $\cdot 3.5(0.7)$ & $25.8(3.2)$ & & $20.0(1.6)$ & & $15.5(3.2)$ \\
\hline \multicolumn{11}{|c|}{$\mathrm{Fe}(\mathrm{III})(\mu \mathrm{M})$} \\
\hline $10 \mathrm{~cm}$ & $0.2(0.1)$ & & $0.3(0.2)$ & & $0.9(0.4)$ & $0.2(0.1)$ & & $0.3(0.1)$ & & $1.6(0.5)$ \\
\hline $40 \mathrm{~cm}$ & $2.3(2.3)$ & & $0.1(0.1)$ & $<$ & $\cdot 2.9(1.7)$ & $0.1(0.1)$ & & $0.8(0.3)$ & & $0.2(0.1)$ \\
\hline \multicolumn{11}{|c|}{ Hydrogen sulfide $(\mu \mathrm{M})$} \\
\hline $10 \mathrm{~cm}$ & $\cdot 4.9(1.7)$ & & $\cdot 2.6(1.0)$ & & $<1.0$ & $25.2(5.0)$ & $>$ & $10.5(3.5)$ & $>$ & $1.2(0.2)$ \\
\hline $40 \mathrm{~cm}$ & $8.7(1.9)$ & $>$ & $2.4(0.6)$ & & $<1.0$ & $6.5(1.5)$ & & $5.5(2.1)$ & & $3.0(0.9)$ \\
\hline
\end{tabular}

in the same system (Osgood \& Zieman 1993). As expected, the dominant form of measured soluble nitrogen was ammonium with lower concentrations of nitrate/nitrite (Table 3). Only trace concentrations of nitrite were found in these sites, therefore concentrations of oxidized nitrogen are reported as the sum of nitrate and nitrite. Organic nitrogen was the dominant component of the total nitrogen, while organic phosphorus made up a lower percentage of the total sediment phosphorus. Organic nitrogen, and in one case, phosphorus were higher in the root zone of the marsh site compared to the sand flat site (Table 3). The main difference in inorganic nutrient concentrations between the sites was at the low elevation station, where soluble and extractable ammonium and soluble phosphate were approximately 10 times higher at the sand flat site (Table 3). There was a significant decrease in soluble ammonium and phosphate toward the high elevation station at the sand flat site (Table 3). There were no consistent significant differences between stations at the marsh site, except with lower values of organic and extractable nitrogen and soluble phosphate at the high elevation station.

The results of the depth profile at the sand flat display a general increase with depth in soluble nutrients ranging in concentration from 50 to $750 \mu \mathrm{M}$ for ammonium and 10 to $150 \mu \mathrm{M}$ for phosphate (Fig. 3). This trend was similar at all stations, but was most pronounced at the low and intermediate elevation stations. The first peak for both ammonium and phosphate was approximately $70 \mathrm{~cm}$ below the surface at the low elevation station. The phosphate peak at this depth is the largest in the profile. Below $70 \mathrm{~cm}$ at this station, nutrient concentration became variable with ammonium and phosphate peaks at approximately $130 \mathrm{~cm}$ below the surface and an additional ammo- 


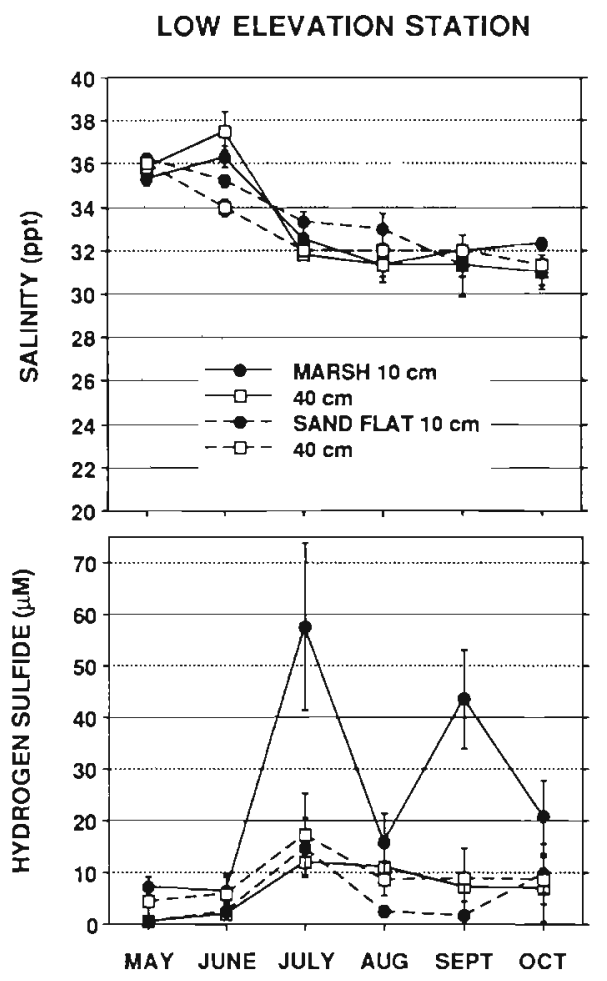

INTERMEDIATE ELEVATION STATION

HIGH ELEVATION STATION
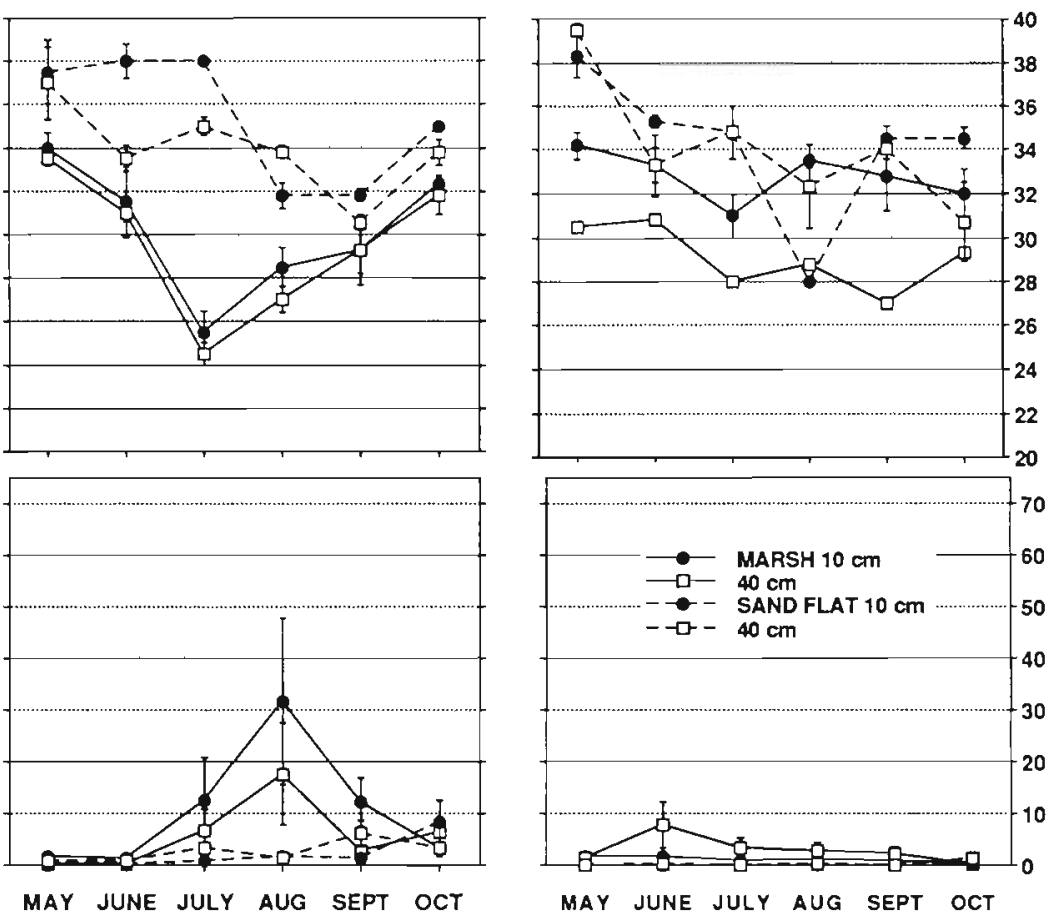

Fig. 2. Pore water salinity and hydrogen sulfide from May through October, 1993, at the sand flat and marsh sites

Table 3. Substrate nutrient chemistry of a storm-deposited sand flat and undisturbed marsh. Data are average of 6 mo (May to October, 1993) except nitrate/nitrite. ' $<$ ' and ' $>$ ' indicate significant differences between stations ( $p<0.05)$. SE given in parentheses

\begin{tabular}{|c|c|c|c|c|c|c|c|}
\hline & $\begin{array}{c}\text { Low } \\
\text { Elevation }\end{array}$ & $\begin{array}{l}\text { Sand flat site } \\
\text { Intermediate } \\
\text { Elevation }\end{array}$ & $\begin{array}{l}\text { High } \\
\text { Elevation }\end{array}$ & $\begin{array}{c}\text { Low } \\
\text { Elevation }\end{array}$ & $\begin{array}{l}\text { Marsh site } \\
\text { Intermediate } \\
\text { Elevation }\end{array}$ & & $\begin{array}{l}\text { High } \\
\text { Elevation }\end{array}$ \\
\hline \multicolumn{8}{|l|}{ Nitrogen } \\
\hline \multicolumn{8}{|c|}{ Soluble ammonium ( $\mu \mathrm{M})$} \\
\hline $10 \mathrm{~cm}$ & $\cdot 219.9(23.4)$ & $>\cdot 48.6(6.2)$ & $6.3(1.1)$ & $28.3(7.8)$ & $3.7(0.5)$ & & $5.1(1.3)$ \\
\hline $40 \mathrm{~cm}$ & $\cdot 272.0(25.0)$ & $>\cdot 52.3(6.2)$ & $>\quad 16.9(4.8)$ & $5.0(0.8)$ & $6.6(1.3)$ & & $3.1(0.4)$ \\
\hline \multicolumn{8}{|c|}{ Soluble nitrate + nitrite $(\mu \mathrm{M})$} \\
\hline $10 \mathrm{~cm}$ & $\cdot 8.2(3.4)$ & $3.9(0.3)$ & $4.8(0.0)$ & $2.5(0.3)$ & $3.3(2.5)$ & & $1.7(0.6)$ \\
\hline $40 \mathrm{~cm}$ & $3.9(0.8)$ & $3.2(0.3)$ & $4.7(0.1)$ & $5.1(3.2)$ & $3.6(0.1)$ & & $5.0(3.8)$ \\
\hline \multicolumn{8}{|c|}{ Organic nitrogen ( $\left.\mu \mathrm{mol} \mathrm{g}{ }^{-1}\right)$} \\
\hline $10 \mathrm{~cm}$ & $\cdot 8.6(1.4)$ & $\cdot 7.0(2.8)$ & $5.4(1.3)$ & $14.3(2.5)$ & $16.6(3.8)$ & $>$ & $7.2(1.7)$ \\
\hline $40 \mathrm{~cm}$ & $7.4(1.3)$ & $8.5(1.7)$ & $6.0(0.9)$ & $3.2(0.6)$ & $2.8(0.7)$ & & $5.6(1.3)$ \\
\hline \multicolumn{8}{|c|}{ Extractable ammonium ( $\left.\mathrm{mmol} \mathrm{g}^{-1}\right)$} \\
\hline $10 \mathrm{~cm}$ & $\cdot 0.71(0.25)$ & $0.20(0.06\}$ & $0.03(0.01)$ & $0.14(0.02)$ & $0.48(0.14)$ & $>$ & $0.15(0.04)$ \\
\hline $40 \mathrm{~cm}$ & $\cdot 0.96(0.24)$ & $0.32(0.09)$ & $0.03(0.01)$ & $0.04(0.01)$ & $0.04(0.01)$ & & $0.03(0.01)$ \\
\hline \multicolumn{8}{|c|}{ Phosphorus } \\
\hline \multicolumn{8}{|c|}{ Soluble phosphate $(\mu \mathrm{M})$} \\
\hline $10 \mathrm{~cm}$ & $\cdot 105.5(6.1)$ & $>12.2(2.39)$ & $4.0(0.7)$ & $25.9(4.0)$ & $9.9(3.1)$ & & $0.9(0.3)$ \\
\hline $40 \mathrm{~cm}$ & $\cdot 94.1(7.1)$ & $>16.5(2.0)$ & $3.7(0.7)$ & $13.7(3.0)$ & $12.4(3.3)$ & $>$ & $1.3(0.3)$ \\
\hline \multicolumn{8}{|c|}{ Organic phosphorus ( $\mathrm{umol} \mathrm{g}^{-1}$ ) } \\
\hline $10 \mathrm{~cm}$ & $0.56\{0.19\}$ & $\cdot 0.17(0.13)$ & $0.82(0.62)$ & $1.42(0.70)$ & $1.54(0.66)$ & & $2.05(0.56)$ \\
\hline $40 \mathrm{~cm}$ & $0.31(0.14)$ & $0.10(0.05)$ & $1.13(0.62)$ & $1.38(0.42)$ & $1.32(0.33)$ & & $1.42(0.47)$ \\
\hline \multicolumn{8}{|c|}{ Inorganic phosphorus $\left(\mu \mathrm{mol}^{-1} \mathrm{~g}^{-1}\right)$} \\
\hline $10 \mathrm{~cm}$ & $4.9(0.6)$ & $4.5(0.5)$ & $3.7(0.5)$ & $2.8(0.4)$ & $2.6(0.4)$ & & $4.3(2.1)$ \\
\hline $40 \mathrm{~cm}$ & $4.5(0.6)$ & $4.0(0.5)$ & $3.5(0.5)$ & $2.4(0.4)$ & $2.0(0.4)$ & & $2.0(0.4)$ \\
\hline
\end{tabular}


Distance to subtidal boundary $(\mathrm{m})$

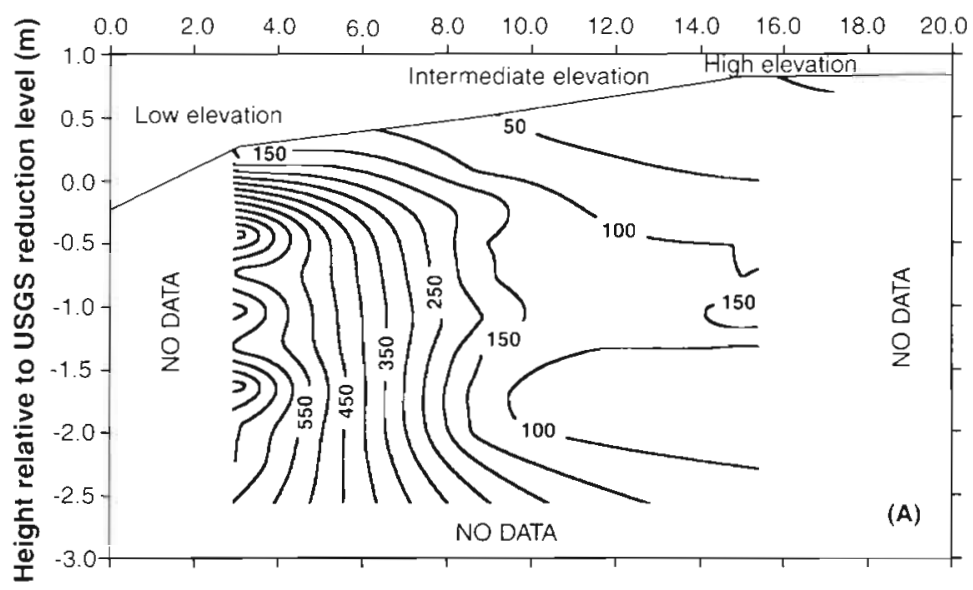

Distance to subtidal boundary $(\mathrm{m})$

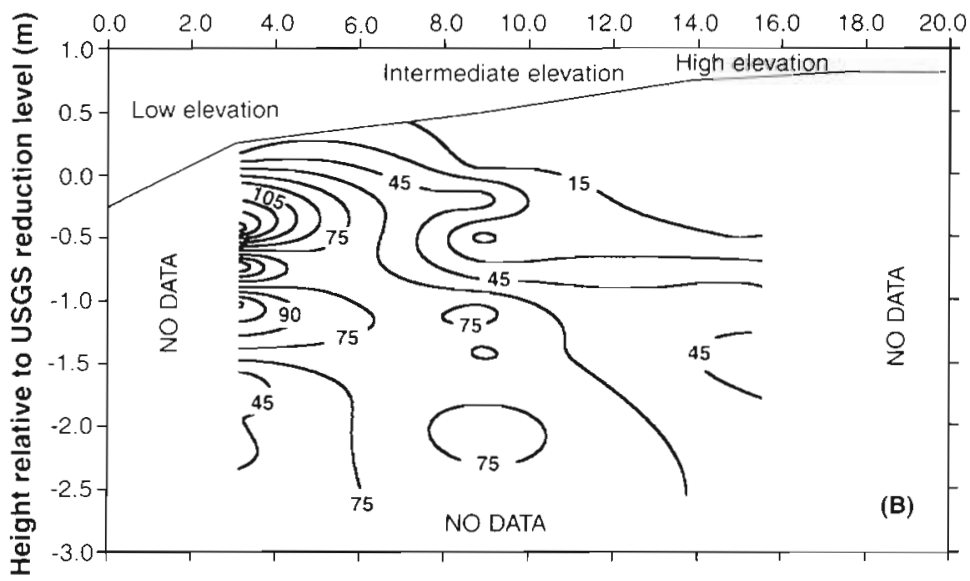

Fig. 3. Depth profile from 10 to $250 \mathrm{~cm}$ of (A) pore water ammonium and (B) phosphate, at the sand flat site increase within a range from 10 to $45 \mu \mathrm{M}$, primarily at the low elevation station, at approximately $220 \mathrm{~cm}$ below the marsh surface.

\section{Primary production}

Both Spartina alterniflora production $(\mathrm{p}=0.0001)$ and maximum stem density $(p<0.02)$ were significantly higher at the low elevation compared to the intermediate elevation station. Production for the low elevation station was $2735 \mathrm{~g}$ dry biomass $\mathrm{m}^{-2}$ (growing season) $^{-1}$ [standard error $(\mathrm{SE})=323.3$ ] with a maximum stem density of 306 stems $\mathrm{m}^{-2}(\mathrm{SE}=23.5)$. Production for the intermediate elevation station was $382 \mathrm{~g}$ dry biomass $\mathrm{m}^{-2}$ (growing season $)^{-1}(\mathrm{SE}=27.5)$ with a maximum stem density of 213 stems $\mathrm{m}^{-2}(\mathrm{SE}=22.9$ ).

\section{DISCUSSION}

\section{Physical characteristics and marsh development}

Both sites had physical attributes characteristic of developing intertidal zones on barrier islands. Specifically, marshes developing in this type of system are characterized by a high sand, low silt and clay component, and low organic content (Godfrey \& Godfrey 1976, Frey \& Basan 1978). In situ substrate development has apparently resulted in a significantly higher organic content at 10 , but not at $40 \mathrm{~cm}$ in the young marsh site, compared to the sand flat site. Higher organic content, restricted to this relatively shallow depth at the marsh site, would be consistent with the early stages of vertical accretion as described in part by the bi-directional model of marsh development (Redfield 1972). The similarity in fine-grained sediment at $10 \mathrm{~cm}$ between sites suggests that either sufficient inorganic accretion has taken place at the sand flat since deposition or there was redistribution of material during deposition.

\section{Chemical characteristics and marsh development}

Lower hydrogen sulfide and higher redox potential and $\mathrm{pH}$ at the sand flat site were all consistent with the lower organic content at that site compared to the
Concentrations of soluble ammonium at the marsh site were more consistent with depth, but did show some
At the marsh site, the highest concentrations of soluble phosphate were approximately $40 \mathrm{~cm}$ or less below the surface of the low and intermediate stations with a consistent decrease with depth at all stations (Fig. 4). 
young marsh site. A higher organic content at the marsh site would support greater sulfate reduction, resulting in higher hydrogen sulfide and lower redox potential. Lower pH would also be expected with oxidation of higher concentrations of hydrogen sulfide (Gardner 1973). The lower salinity at the marsh site can be explained by greater freshwater drainage at this site associated with the bordering upland (D. Osgood unpubl. data). A substantial upland interface, in the form of a vegetated dune system, had not developed at the sand flat site.

The similarity in extractable ammonium and inorganic phosphorus between the sites at the intermediate and high elevation stations can probably be attributed to the similarity in sediment type between the sites. However, there was a large difference in inorganic, soluble nutrient pools between the 2 sites, with higher ammonium concentrations at the low and intermediate elevation stations and higher phosphate concentrations at the low elevation station of the sand flat site. The more frequently flooded stations with lower redox potentials should have had higher soluble nutrient concentrations, but it is not obvious why the concentrations of soluble nutrients at the sand flat were greater than in the marsh or why the concentrations were so high in sediment with a high sand content. Further explanation is derived from examination of the depth profile of soluble nutrient concentrations.

The magnitude of the increase in soluble nutrient concentrations with depth at the sand flat site would suggest a source of nutrients from depth. The transects were positioned above an intertidal mudflat that ran along the edge of a $50 \mathrm{~m}$ wide channel that existed previous to the storm (Fig. 1). Peaks in ammonium and phosphate concentrations at approximately $70 \mathrm{~cm}$ below the low elevation stations (Fig. 3) correspond with the estimated depth to the mudflat and suggest that the higher clay content of this buried layer could supply a high concentration of nutrients to other depths through advection or diffusion. The nutrient concentration peaks observed at approximately $120 \mathrm{~cm}$ below the high elevation station also coincide with the estimated depth to the buried layer.

It is unlikely that nutrients are being supplied from below the root zone at the marsh site, at least not at the same scale as at the sand flat site. There was some evidence of an increase with depth of soluble ammonium,
Distance to subtidal boundary (m)

$\begin{array}{lllllllllllllll}0 & 5.0 & 10.0 & 15.0 & 20.0 & 25.0 & 30.0 & 35.0 & 40.0 & 45.0 & 50.0 & 55.0 & 60.0 & 65.0 & 70.0\end{array}$ $\begin{array}{llllllll}1 & 1 & 1 & 1 & 1 & 1 & 1 & 1\end{array}$

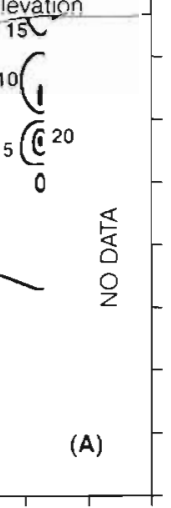

Distance to subtidal boundary $(\mathrm{m})$

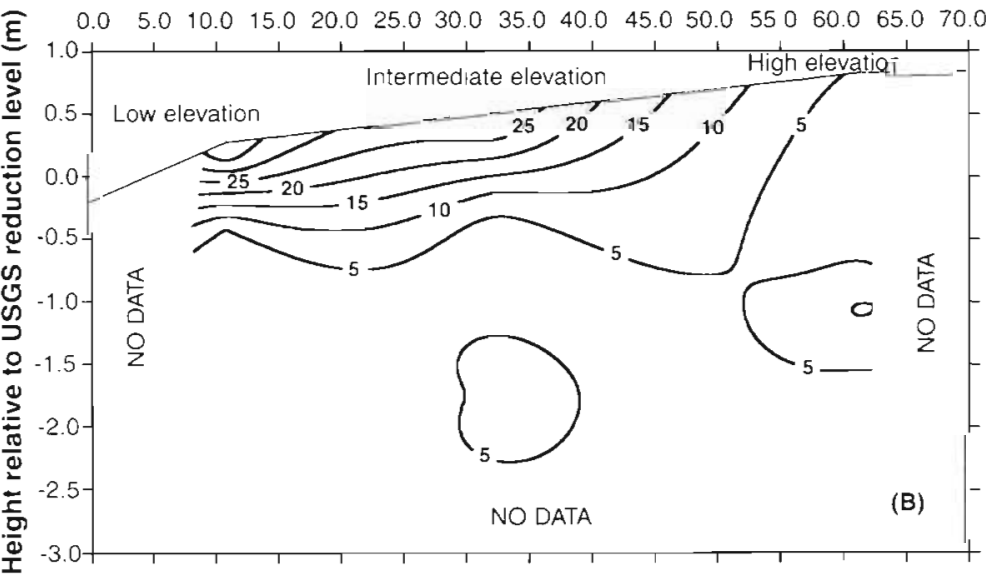

Fig. 4. Depth profile from 10 to $250 \mathrm{~cm}$ of (A) pore water ammonium and (B) phosphate, at the young marsh site

but this increase was an order of magnitude less than at the sand flat site. A slightly lower ammonium concentration near the surface might be due to macrophyte uptake and/or nitrification/denitrification that could lead to a net loss of ammonium from the root zone. The lack of increase with depth of soluble phosphate further suggests that nutrient supply is not primarily from below the root zone at the marsh site, but more likely from within the root zone itself. Higher phosphate concentrations in the root zone are consistent with mineralization of organic matter or inorganic sediment deposition as potential sources of this nutrient.

The greater organic nitrogen content at both sites relative to inorganic extractable nitrogen is consistent with findings in other marshes, but overall concentrations were lower in this study compared to those normally associated with mature marshes (Buresh et al. 1980, Lindau \& Hossner 1981, Craft et al. 1991, Osgood \& Zieman 1993). The lower extractable ammonium, 
compared to more mature marshes, is consistent with the idea that there would be less time for accumulation of inorganic nutrients associated with tidal sediment input or mineralization processes (DeLaune et al. 1981, Morris \& Bowden 1986). A lower organic nitrogen may simply be a consequence of the low organic content of these developing intertidal zones.

In contrast to nitrogen, extractable phosphorus concentration was higher than organic phosphorus concentration. The reverse of this pattern could apply to immature marshes if the relatively oxidized conditions of these marshes leads to a larger extractable pool of phosphate, particularly as iron-phosphate compounds. It has been suggested that the formation of iron-phosphate compounds may not be as important as iron-sulfur compounds in salt marshes lOdum 1988, Chambers $\&$ Odum 1990). While insoluble iron compounds were not measured in this study, we speculate that iron-sulfur compounds may not be as important as iron-phosphate compounds in young, sandy marshes which have a lower supply of hydrogen sulfide compared to older marshes. Craft et al. (1991) also attributed a high total phosphorus to iron-phosphate compounds in a young, created marsh in North Carolina, in contrast to the predominance of the organic form of phosphorus, as was the case in their mature, natural marsh.

Nutrient pools in created marshes have been shown to become equivalent to nutrient pools in established marshes in 2 to 15 yr (Craft et al. 1988, Lindau \& Hossner 1981). Osgood \& Zieman (1993) demonstrated that root zone nutrient standing stocks were equivalent between a 10 to $13 \mathrm{yr}$ old marsh and a marsh that was hundreds of years old. In the case of the developing systems in this study, most organic nutrient concentrations were significantly lower in the sand flat site $(2$ yr old) compared to the 14 to 16 yr old marsh site. Craft et al. (1988) suggested that nutrients associated with macroorganic matter would increase more rapidly than sediment nutrients in created marshes in North Carolina. This is consistent with the higher organic nutrient concentrations, rather than inorganic concentrations, at the marsh site compared to the sand flat site. This study demonstrates that it takes longer than $2 \mathrm{yr}$ for the organic concentration of nutrients to accumulate and we suggest that this fraction of nutrients at the sand flat site will probably remain low until the time of more complete colonization by emergent macrophytes. In contrast, the soluble and extractable inorganic nutrient standing stocks were higher at the sand flat site compared to the marsh site. This observation does not follow a pattern of net accumulation of nutrients with time. In cases where a nutrient-rich source is buried, as described above, inorganic nutrient standing stocks can actually be elevated in an immature system relative to mature marshes.
Odum (1969) presented the idea that young ecosystems, relative to older ecosystems, would rely more on external nutrient input to sustain primary productivity and that the nutrient supply in tidal marshes originates from flushing of tidal water. The presence of an antecedent nutrient source buried at depth at the sand flat site suggests that the external nutrient source may not come directly from the tidal water. We can only speculate as to how long the mud flat could serve as the primary source of nutrients, but obviously consideration needs to be given to the stratigraphy of a new deposit, as this study demonstrates it can have an important influence over early sediment chemistry. The young marsh site, with nutrient concentrations higher in the root zone or at least more similar with depth than at the sand flat site, is more likely to emulate older ecosystems which internally recycle nutrient pools.

Various aspects of nutrient cycling such as mineralization rates, nitrogen fixation or nitrification/denitrification rates were not addressed in this study. These processes are important in marsh sediments and until such processes are studied in the context of natural marsh development it will be unclear what role they may play in development of nutrient standing stocks

\section{Import/export of nutrients and marsh development}

In a summary by Nixon (1980), marshes are described as net exporters, importers, and/or transformers of tidal nutrients. Several authors have suggested that young ecosystems, with lower nutrient standing stocks, tend to be net importers of tidal nutrients relative to older systems which act as net exporters (Vitousek \& Reiners 1975, Craft et al. 1989, Childers et al. 1993). The significantly higher inorganic nutrient concentrations at the sand flat site are inconsistent with the concept of net import in immature systems. Again, the presence of a buried, nutrient-rich source at the sand flat leads to pore water concentrations much higher than flooding water concentrations ( $\mathrm{D}$. Osgood unpubl. data). Therefore, this site could act as a net exporter of nutrients. The marsh site has lower inorganic nutrient concentrations compared to the sand flat site and below the root zone there are lower inorganic nutrient concentrations than found in older marshes elsewhere in the Virginia Coast Reserve (Osgood \& Zieman 1993). As was already pointed out, organic nutrient concentrations are lower at the marsh site than found in more mature marshes. Thus, the young marsh site is more likely to import inorganic and organic nutrients over time.

No direct measurement of flux to and from the water column was made in this study; however, this work 
suggests that the depositional history of young barrier island marshes needs to be considered in questions of nutrient standing stock development and age-related ecosystem processes such as import/export of nutrients. This situation may not be unique to this particular event and may in fact be a general occurrence with marsh development on barrier islands. The intertidal portion of any substantial sediment deposition on barrier islands should bury 1 of 3 sediment types: organicrich marsh, mud flat or channel bottom, or sand. Several scenarios favor development in which there are higher concentrations of inorganic nutrients, relative to flooding water, in very early stages of developing sediments, which could lead to a net export of nutrients from a young system.

\section{Vegetation zonation and Spartina alterniflora production gradients}

De Leeuw et al. (1993) demonstrated that vegetation zonation in a 65 to $140 \mathrm{yr}$ old barrier island marsh in The Netherlands does not reflect a successional history. The authors suggest that the dominance of aeolian processes provided the general relief in the intertidal zone prior to colonization by marsh species. The marsh that developed was suggested to have started out with a typical intertidal zonation for that region and the present relief of the marsh still reflected the originally deposited relief. Our results would seem to indicate that, in addition to topographic relief, initial gradients in intertidal sediment chemistry also exist such that colonization on the sand flat will conform to traditional patterns of Mid-Atlantic Coast marsh zonation.

It is well known that gradients in intertidal vegetation reflect different growing conditions along the intertidal zone, sometimes coupled with competition among species better adapted for certain edaphic conditions (Adams 1963). Succession in intertidal marshes is dictated primarily by various environmental parameters rather than through autogenic succession normally associated with terrestrial communities (Mitsch \& Gosselink 1986). There is little information available on whether certain environmental conditions are in place prior to natural intertidal colonization and whether gradients in those conditions change with succession. Based on observations of other marshes in the system, along with gradients in various sediment parameters, the colonization of the sand flat should lead to a submerging coast marsh type, characterized by distinct high and low marsh zones as seen elsewhere along the Atlantic Coast (Stevenson et al. 1986).

Competitive interactions under the relatively more oxidized edaphic conditions at the high elevation sta- tion of the sand flat will probably result in the vegetation ultimately dominating that environment. Bertness \& Ellison (1987) have determined that interspecific competition is important in dictating species distribution in New England high marsh environments characterized by Spartina patens, Distichlis spicata, and Salicornia europaea, with Juncus gerardi along the terrestrial border. The species within the elevation range that encompasses the relatively narrow fringe of high marsh throughout the Virginia Coast Reserve, including the marsh site in this study, are S. patens, $D$. spicata, Limomium carolinium, and Salicornia virginica. It is expected that the same species could colonize near the high elevation station at the sand flat. Observations of sparse $S$, patens and D. spicata shoots in the immediate area of the high elevation stations at the sand flat further suggest the species type most likely to colonize the sand flat at that elevation.

Species such as Spartina patens are unable to tolerate the more frequently flooded, anaerobic sediments of the low marsh and it is thought that low marsh vegetation, typically Spartina alterniflora on the Atlantic and Gulf Coasts, is competitively displaced to the lower intertidal elevations by species such as $S$. patens (Gleason \& Zieman 1981, Bertness \& Ellison 1987). It is of little surprise to observe $S$. alterniflora at the low and intermediate station of the sand flat, which suggests it should be the dominant vegetation in the lower portion of the intertidal zone.

The soluble nutrient standing stock at the sand flat is similar to or higher than other marsh sites in the system, therefore direct nutrient limitation should not be a factor in the successful colonization of the sand flat by Spartina alterniflora, but may instead play a part in the development of a production gradient across the low marsh. Growing conditions should be most favorable for $S$. alterniflora at the low elevation station based on the higher soluble nutrient concentrations at this station relative to the intermediate elevation station. In contrast to the growing conditions at the low elevation station, plants colonizing the intermediate elevation station will be exposed to a lower concentration of nutrients, possibly resulting in a less productive form of $S$. alterniflora. The presence of these 2 growth forms at the respective elevations at the marsh site lends further support to this argument.

Redox potential did not differ significantly between the 2 lower elevation stations at the sand flat site and therefore should not influence production of Spartina alterniflora between these stations. In addition, pore water salinity and hydrogen sulfide found at the sand flat are within tolerable limits for $S$. alterniflora and differences between the lower stations are probably not great enough to have a significant physiological effect on the growth of this marsh grass (Haines \& Dunn 
1976, Bradley \& Morris 1990, 1991). Linthurst (1980) showed that optimum growing conditions for $S$. alterniflora were at $\mathrm{pH} 6$, compared to $\mathrm{pH} 4$ and 8 . The circumneutral $\mathrm{pH}$ found at the sand flat indicates that this factor should also not dictate vegetation patterns during colonization.

The existing production gradient in Spartina alterniflora at the marsh site cannot be readily explained by patterns in the measured sediment parameters. Slightly higher salinity and hydrogen sulfide at the low elevation station, relative to the intermediate station, could represent additional stress on S. alterniflora. However, the greater production of $S$. alterniflora found at the lower elevation station would suggest that these parameters are not adversely affecting growth relative to that of $S$. alterniflora at the intermediate elevation station. There was also no significant difference between these stations in soluble ammonium or nitrate/nitrite concentrations. Current research by the authors demonstrates that differences in subsurface hydrology lead to a greater porewater flux through the tall-form S. alterniflora root zone. Further evidence demonstrates that the mechanism behind the higher production at this zone is a greater flux of nitrogen, which leads to a greater exposure to this nutrient under nitrogen-limited conditions (D. Osgood unpubl. data).

Acknowledgements. The authors acknowledge the following individuals for their assistance with field and lab work: Jeff Osgood, John Walsh, Jamie Watt, and David Yozzo. This study was funded by a William $\mathrm{H}$. Bannon Research award from the Department of Environmental Sciences, University of Virginia, presented to D.T.O. and the Virginia Coast Reserve/Long Term Ecological Research Project (NSF Grant No. DEB-9211772) operated by the Department of Environmental Sciences, University of Virginia.

\section{LITERATURE CITED}

Abacus Concepts. (1989). SuperANOVA. Abacus Concepts, Inc., Berkeley

Adams, D. A. (1963). Factors influencing vascular plant zonation in North Carolina salt marshes. Ecology 44: 445-456

Bertness, M. D., Ellison, A. M. (1987). Determinants of pattern in a New England salt marsh plant community. Ecol. Monogr. 57: 129-147

Bradley, P. M., Morris, J. T (1990). Influence of oxygen and sulfide concentration on nitrogen uptake kinetics in Spartina alterniflora. Ecology 71: 282-287

Bradley, P. M., Morris, J. T. (1991). The influence of salinity on the kinetics of $\mathrm{NH}_{4}{ }^{+}$uptake in Spartina alternifiora. Oecologia 85: 375-380

Brower, J. E., Zar, J. H. (1984). Field and laboratory methods for general ecology, 2nd edn. Wm. C. Brown, Inc., Dubuque, IA

Buresh, R. J., DeLaune, R. D., Patrick, W. H. Jr (1980). Nitrogen and phosphorus distribution and utilization by Spartina alterniflora in a Louisiana Gulf Coast marsh. Estuaries 3: 111-121

Caton, R. D. Jr (1977). Reference electrodes. In: Ewing, G. W. (ed.) Topics in chemical instrumentation. American Chemical Society, Washington, DC, p. 112-119

Chambers, R. M., Fourqurean, J. W. (1991). Alternative criteria for assessing nutrient limitation of a wetland macrophyte (Peltandra virginica (L.) Kunth). Aquat. Bot. 40: $305-320$

Chambers, R. M., Odum, W. E. (1990). Porewater oxidation, dissolved phosphate, and the iron curtain: iron-phosphate relations in tidal freshwater marshes. Biogeochemistry 10 : $37-52$

Childers, D. L., Cofer-Shabica, S., Nakashima, L. (1993). Spatial and temporal variability in marsh-water column interactions in a southeastern USA salt marsh estuary. Mar. Ecol. Prog. Ser. 95: 25-38

Cline, J. D. (1969). Spectrophotometric determination of hydrogen sulfide in natural waters. Limnol. Oceanogr. 14: $454-458$

Craft, C. B., Broome, S. W., Seneca, E. D. (1988). Nitrogen, phosphorus and carbon pools in natural and transplanted marsh soils. Estuaries 11: 272-280

Craft, C. B., Broome, S. W., Seneca, E. D. (1989). Exchange of nitrogen, phosphorus, and organic carbon between transplanted marshes and estuarine waters. J. environ. Qual. 18: $206-211$

Craft, C. B., Seneca E. D., Broome, S. W. (1991). Porewater chemistry of natural and created marsh soils. J. exp. mar. Biol. Ecol. 152: 187-200

Dame, R., Childers, D., Koepfler, E. (1992). A geohydrologic continuum theory for the spatial and temporal evolution of marsh-estuarine ecosystems. Neth. J. Sea Res. 30: 63-72

Davis, R. E., Dolan, R. (1992). The "All Hallows' Eve" coastal storm. J. coast. Res. 8: 978-983

Delaune, R. D., Reddy, C. N., Patrick, W. H. Jr (1981). Accumulation of plant nutrients and heavy metals through sedimentation processes and accretion in a Louisiana salt marsh. Estuaries 4: 328-334

De Leeuw, J., De Munck, W., Olff, H., and Bakker, J. P. (1993). Does zonation reflect the succession of salt-marsh vegetation? A comparison of an estuarine and a coastal bar island marsh in The Netherlands. Acta bot. neerl. 42: 435-445

Frey, R. W., Basan, P. B. (1978). Coastal salt marshes. In: Davis, R. A. Jr (ed.) Coastal sedimentary environments. Springer-Verlag, New York, p. 101-159

Gale, P. M., Reddy, K. R., Graetz, D. A. (1993). Nitrogen removal from reclaimed water applied to constructed and natural wetland microcosms. Water environ. Res. 65: $162-168$

Gardner, L. R. (1973). The effect of hydrologic factors on the porewater chemistry of interstitial tidal marsh sediments. Southeast. Geol. 15: 17-28

Gibbs, M. M. (1979). A simple method for the rapid determination of iron in natural waters. Water Res. 13: 295-297

Gleason, M. L. Zieman, J. C. (1981). Influence of tidal inundation on internal oxygen supply of Spartina alterniflora and Spartina patens. Estuar. coast. Shelf Sci. 13: 47-57

Godfrey, P. J., Godfrey, M. M. (1976). Barrier island ecology of Cape Lookout National Seashore and vicinity, North Carolina. National Park Service Monograph Series No. 9, Washington, DC

Haines, B. L., Dunn, E. L. (1976). Growth and resource allocation responses of Spartina alterniflora Loisel. to three levels of $\mathrm{NH}_{4}-\mathrm{N}, \mathrm{Fe}$, and $\mathrm{NaCl}$ in solution culture. Bot. Gaz. 137: 224-230

Haines, E., Chalmers, A., Hanson, R., Sherr, B. (1977). Nitrogen pools and fluxes in a Georgia salt marsh. In: Wiley, M (ed.) Estuarine processes. Academic Press, New York, p. 241-254 
Hayden, B. P., Dueser, R. D., Callahan, J. T., Shugart, H. H. (1991). Long-term research at the Virginia Coast Reserve: modeling a highly dynamic environment. Biosci. 41. $310-318$

Jones, M. N. (1984). Nitrate reduction by shaking with cadmium: alternative to cadmium columns. Water Res. 18: 643-646

Krovetz, D. O., Spitler, J. R., Porter, J. H. (1993). Tide data for the Virginia Coast Reserve, 1993. Virginia Coast Reserve/ Long-Term Ecological Research Project, Charlottesville

Lindau, C. W., Hossner, L. R. (1981). Substrate characterization of an experimental marsh and three natural marshes. J. Soil Sci. Soc. Am. 45: 1171-1176

Linthurst, R. A. (1980). An evaluation of aeration, nitrogen, $\mathrm{pH}$ and salinity as factors affecting Spartina alterniflora growth: a summary. In: Kennedy, V. S. (ed.) Estuarine perspectives. Academic Press, New York, p. 235-247

Mitsch, W. J., Gosselink, J. G. (1986). Wetlands. Van Nostrand Reinhold, New York

Morris, J. T. (1988). Pathways and controls of the carbon cycle in salt marshes. In: Hook, D. D., et al. (eds.) The ecology and management of wetlands, Vol. 1. Ecology of wetlands. Croom Helm, London, p. 497-510

Morris, J. T., Bowden, W. B. (1986). A mechanistic, numerical model of sedimentation, mineralization, and decomposition for marsh sediments. J. Soil Sci. Soc. Am. 50: 96-105

Morris, J. T., Haskin, B. (1990). A five-year record of aerial primary production and stand characteristics of Spartina alterniflora. Ecology 71: 2209-2217

Nixon, S. W. (1980). Between coastal waters and coastal waters: a review of 20 years of speculation and research

This article was presented by G. W. Thayer (Senior Editorial Advisor), Beaufort, N. Carolina, USA on the role of saltmarshes in estuarine productivity and water chemistry. In: Hamilton, P., MacDonald, K. B. (eds.) Estuarine and wetland processes. Plenum Press, New York, p. 437-525

Odum, E. P. (1969). Strategy of ecosystem development. Science 164: $262-270$

Odum, W. E. (1988). Predicting ecosystem development following creation and restoration of wetlands. In: Zelazny, J., Feierabend, J S. (eds.) Proceedings of a conference, Increasing our wetland resources. National Wildlife Federation, Washington, DC, p. 67-70

Osgood, D. T., Zieman, J. C. (1993). Spatial and temporal patterns of substrate physico-chemical parameters in different-aged barrier island marshes. Estuar, coast. Shelf Sci. 37: 421-436

Parsons, T. R., Maita, Y., Lalli, C. M. (1984). A manual of chemical and biological methods for seawater analysis. Pergamon Press, Oxford

Redfield, A. C. (1972). Development of a New England salt marsh. Ecol. Monogr. 42: 201-237

Stevenson, J. C., Ward, L. G., Kearney, M. S. (1986). Vertical accretion in marshes with varying rates of sea level rise. In: Wolfe, D. A. (ed.) Estuarine variability. Academic Press, New York, p. 241-259

Valiela, I., Teal, J. M. (1979). The nitrogen budget of a salt marsh ecosystem. Nature 280: 652-656

Vitousek, P. M., Reiners, W. A. (1975). Ecosystem succession and nutrient retention: a hypothesis. BioSci. 25: 376-381

Wolaver, T G., Zieman, J. C. (1984). The role of tall and medium Spartina alterniflora zones in the processing of nutrients in tidal water. Estuar. coast. Shelf Sci. 19: 1-13

Manuscript first received: June 29, 1994

Revised version accepted: October 31, 1994 